\title{
On the Importance of Structural and Functional Fatigue in Shape Memory Technology
}

\author{
Jan Frenzel ${ }^{1}$
}

Published online: 6 May 2020

(c) The Author(s) 2020

\begin{abstract}
The present work provides a brief overview on structural and functional fatigue in shape memory alloys (SMAs). Both degenerative processes are of utmost technological importance because they limit service lives of shape memory components. While our fundamental understanding of these two phenomena has improved during the last two decades, there are still fields which require scientific attention. NiTi SMAs are prone to the formation of small cracks, which nucleate and grow in the early stages of structural fatigue. It is important to find out how these micro-cracks evolve into engineering macrocracks, which can be accounted for by conventional crack growth laws. The present work provides examples for the complexity of short crack growth in pseudoelastic SMAs. The importance of functional fatigue has also been highlighted. Functional fatigue is related to the degeneration of specific functional characteristics, such as actuator stroke, recoverable strain, plateau stresses, hysteresis width, or transformation temperatures. It is caused by the accumulation of transformation-induced defects in the microstructure. The functional stability of SMAs can be improved by (1) making phase transformations processes smoother and (2) by improving the material's resistance to
\end{abstract}

This invited article is part of a special issue of Shape Memory and Superelasticity to honor Prof. Dr.-Ing. Gunther Eggeler. This special issue was organized by Prof. Hüseyin Sehitoglu, University of Illinois at Urbana-Champaign, and Prof. Dr.-Ing. Hans Jürgen Maier, Leibniz Universität Hannover.

Jan Frenzel

jan.a.frenzel@rub.de

1 Institute for Materials, Ruhr University Bochum, 44801 Bochum, Germany irreversible processes like dislocation plasticity. Areas in need of further research are discussed.

Keywords Shape memory alloys · Fatigue ·

Microstructure - Short crack growth · High entropy alloys

\section{Introduction}

Shape memory technology has evolved into mature materials engineering field [1]. Two types of shape memory effects (SMEs), a thermal memory (one/two-way effect, $1 / 2 \mathrm{WE}$ ) and mechanical memory (pseudoelasticity, PE), are exploited for advanced applications in aerospace, automotive, construction and environmental engineering, and in the field of medical technology, e.g., [1-6]. Both types of SMEs rely on the martensitic transformation, a solid-state transformation where a high-temperature phase austenite transforms into a low-temperature phase martensite on cooling/mechanical loading [7, 8]. The reverse transformation occurs upon heating/unloading. Many fundamental aspects of the martensitic transformation are well understood, e.g., [7, 9-12]. For the field of shape memory technology, it is important that the formation of martensite is strongly governed by the chemical composition and the microstructure of an alloy [13-18]. This allows to control and to optimize properties and performance of shape memory alloys (SMAs) for specific applications. During the last decades, the evolution of shape memory technology has significantly benefitted from fundamental and application-related research $[19,20]$. The main trends in SMA research were driven by the need for new alloys with high transformation temperatures [21-24] and good fatigue resistance [25-30]. Today, a better understanding of mechanical, functional, and microstructural 
aspects [16-18, 31-36], the possibility of 3D printing [37-40], the medical application of SMAs [41-43], and their use in niche applications such as solid-state refrigeration [44-48], advance the field. However, there are specific issues which still hamper the breakthrough of SMA technology. The two probably most important generic issues are structural and functional fatigue. They both limit the performance and the exploitable service lives of shape memory components.

In 2003, Eggeler et al. [49] highlighted the overriding importance of both, structural and functional fatigue of SMAs, and this is today well appreciated [30, 50-52]. Structural fatigue refers to the nucleation and growth of cracks during cyclic loading, which leads to fatigue failure. In contrast, functional fatigue is related to the degeneration of specific functional characteristics, such as actuator stroke, recoverable strain, plateau stresses, hysteresis width, or transformation temperatures. Functional fatigue is caused by irreversible microstructural changes. In the present work, a short overview on the importance of these two types of degenerative processes is provided and fields in need of further work are identified.

\section{Structural Fatigue}

Research on structural fatigue in SMAs has often been motivated by the requirement for medical implants to withstand a high number of loading/unloading cycles $[27,53,54]$. For example, stents which are implanted in blood vessels in the human body are exposed to pulsatile fatigue. A stent is expected to maintain its integrity for at least 10 years, which, at an average pulse of $70 \mathrm{~min}^{-1}$, corresponds to $3.7 \times 10^{8}$ load cycles. Stents, therefore, have to withstand high-cycle fatigue conditions, with cycle numbers in excess of $10^{8}$. Today, a good understanding of factors and processes affecting fatigue lives has been established, e.g., [25-30, 49, 55, 56]. Depending on loading conditions, one can differentiate between high-cycle and low-cycle fatigue regimes (HCF and LCF), e.g., [25-30]. In the HCF regime, fatigue behavior is governed by microstructural processes which lead to the nucleation and growth of cracks. In contrast, cracks quickly form in the LCF regime, and therefore fatigue lives are controlled by crack propagation. For the nucleation of cracks, the surface quality is of utmost importance. Small surface defects like scratches, pores, notches, wire drawing die marks, etc., act as local stress raisers and thus promote the formation of fatigue cracks. Attempts are made to improve surface quality, for example, by electropolishing [57, 58], or to introduce compressive stresses in surface regions [53, 59]. In the absence of surface defects, the formation of fatigue cracks mainly occurs at small oxide and carbide inclusions
[25] which are related to small amounts of impurities, as documented in [14, 60-62]. The propagation of cracks in SMAs differs from what is known for conventional structural engineering materials. Due to high local stresses in front of crack tips, a stress-induced transformation of martensite occurs [29, 63, 64], such that cracks in SMAs grow into martensitic regions.

In general, structural fatigue follows three different stages: (1) crack nucleation, (2) short crack growth, and (3) macroscopic growth of engineering cracks $[65,66]$. While crack formation, macroscopic crack growth, and fatigue lives were addressed in numerous studies, e.g., [25, 27, 67], the behavior of short cracks in SMAs has not received sufficient attention so far. This stage is significantly important. It has been documented in the literature [25] that NiTi SMAs are prone to the formation of micro-cracks. Rahim et al. [25] have demonstrated that close to 300 micro-cracks per square millimeter surface area form during cyclic loading at a strain amplitude of only $1.9 \%$ within $\approx 2000$ fatigue cycles [25]. It is, therefore, important to understand how short cracks in NiTi SMAs evolve into larger cracks which grow at material-specific rates [68].

In the following, the results of a study [69] are reviewed, where the growth of short cracks in pseudoelastic NiTi wires was investigated using interrupted bending rotation fatigue (BRF) experiments. Details on alloy preparation/ processing and fatigue experiments are documented elsewhere $[14,25,57,69,70]$. The NiTi wire was characterized by a slightly increased oxygen concentration (500 ppm), which allowed to investigate the effects of oxygen-rich inclusions on fatigue. Detailed information on the formation of these inclusions, their crystallographic nature, effects on transformation behavior, etc., are available in the literature, e.g., $[14,60-62]$. The wire was subjected to interrupted BRF testing at human body temperature, which results in specific stress/strain states [71, 72]. The nominal imposed surface strain was $1.9 \%$. After specific numbers of mechanical cycles, the surface of the wire was iteratively investigated by scanning electron microscopy (SEM) to detect and to evaluate the formation and growth of microcracks. A special SEM holder, Fig. 1, was used to monitor a specific surface region of the NiTi wire after increasing load cycles. This allows to follow the growth of one crack during different stages of BRF testing. The SEM holder is presented in Fig. 1a, and the region of interest on the wire sample is shown in Fig. 1 b.

Figure 2 shows parts of the wire surface after 0 (Fig. 2a, initial state), 400 (Fig. 2b), and after 2100 BRF cycles (Fig. 2c). The dark particles represent oxides [14, 25]. The black dot on the left side of the images serves as a reference point. The loading direction is from the left to the right. Cracks which have formed during BRF testing are indicated by arrows, it is difficult to identify them in the 


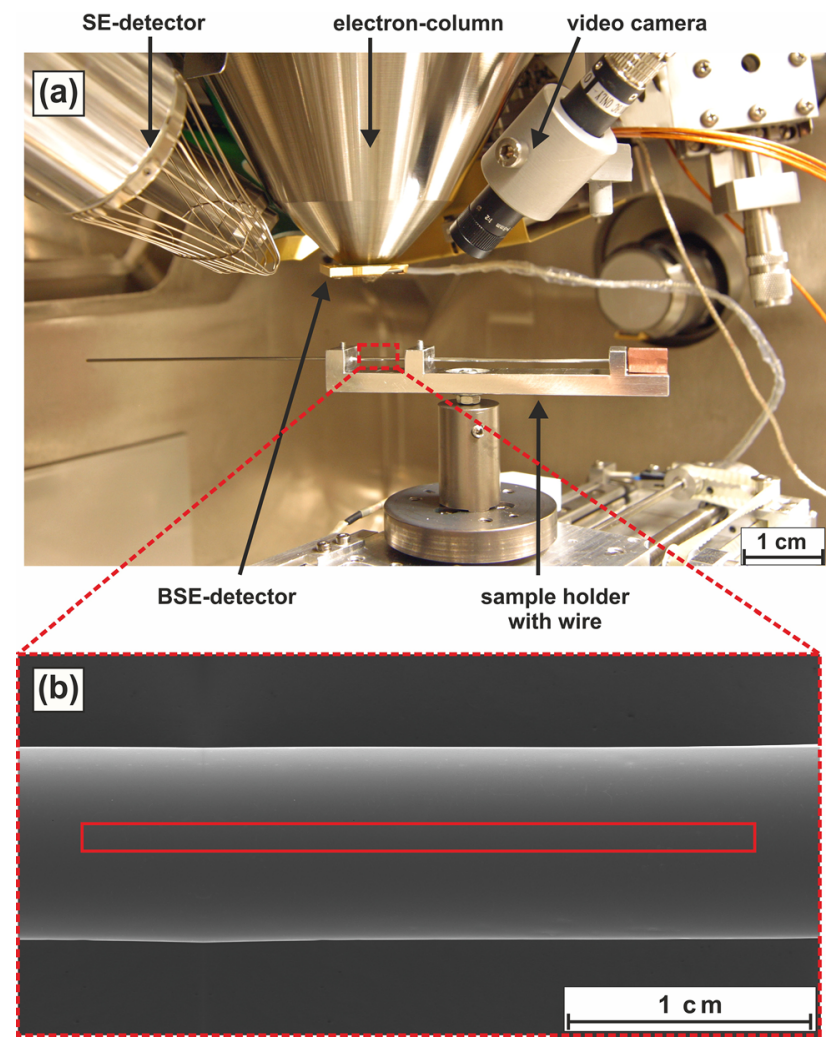

Fig. 1 SEM surface characterization of an electropolished NiTi wire during interrupted BRF experiments. a SEM chamber with sample holder which enables to monitor the same region during fatigue testing. b SEM image of region of interest (red rectangle)

overview SEM micrographs of Fig. 2. After 400 cycles, 4 micro-cracks were observed (Fig. 2b). The number of cracks increased to 9 within 2100 cycles (Fig. 2c).

Micro-crack nucleation and growth are presented in Fig. 3 at a higher magnification. Figure 3 shows two oxide particles which are associated with small voids. These types of defects were referred to as particle/void assemblies (PVAs) in the literature [25]. Voids form when larger inclusions fracture during thermo-mechanical processing [73], e.g., during wire drawing. These PVAs represent dominant crack initiation sites for electropolished NiTi SMAs, where no more severe surface defects are present [25]. Figure 3 shows that cracks form from interface regions between oxide particles, adjacent voids, and the SMA matrix. Figure $3 a-c$ document how the two cracks shown in Fig. 3 grow during the different stages of the fatigue experiment, i.e., during 2100 cycles. As a striking result, it was found, that only one crack, which emanated from the right particle, underwent significant growth. In contrast, the left crack in Fig. 3 showed no increase in length. This is probably due to a stress-shielding effect, caused by the propagation of the larger micro-crack. The observed behavior is not uncommon. In general, the growth

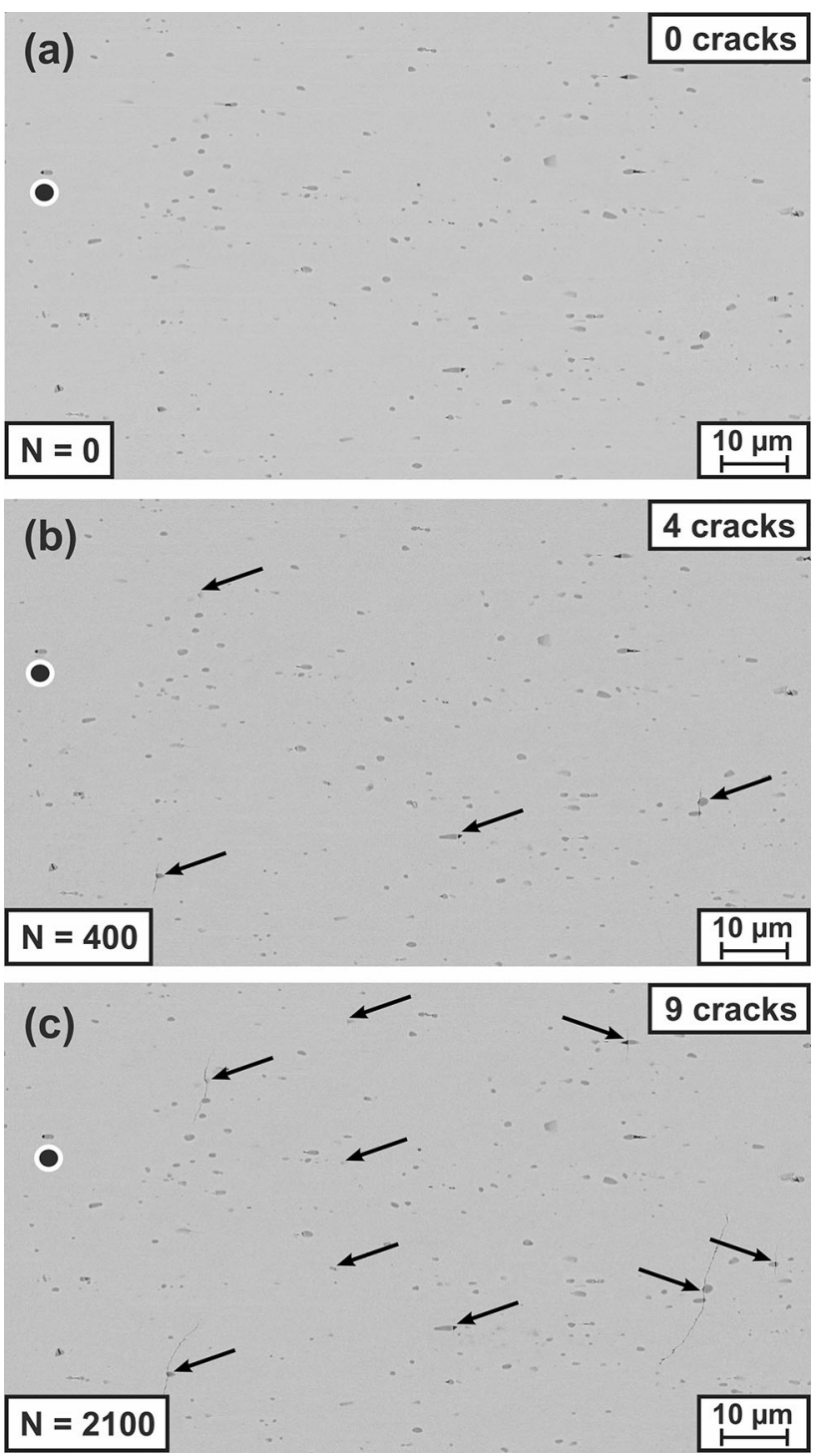

Fig. 2 Formation and growth of short cracks emanating from oxide inclusions during BRF testing. a Initial state. b After 400 cycles. c After 2100 cycles. The black dot indicates the same reference point in all three images

of micro-cracks cannot be rationalized by macroscopic growth models [74-76]. Their behavior is mainly governed by local stresses in different microstructural regions. Furthermore, shielding effects, as exemplarily shown in Fig. 3, play important roles. Not all micro-cracks are able to evolve into macroscopic cracks [74-76].

Figure 4 presents information on how the lengths of different short surface cracks in the NiTi wire evolve during BRF testing. The data sets in Fig. 4 rely on the evaluation of surface crack lengths by quantitative image analysis of 69 cracks during interrupted BRF experiments. The data in Fig. 4 suggest that only a small number of micro-cracks exhibits a significant growth. Fifty cracks did not reach lengths exceeding $25 \mu \mathrm{m}$. Only one single crack 


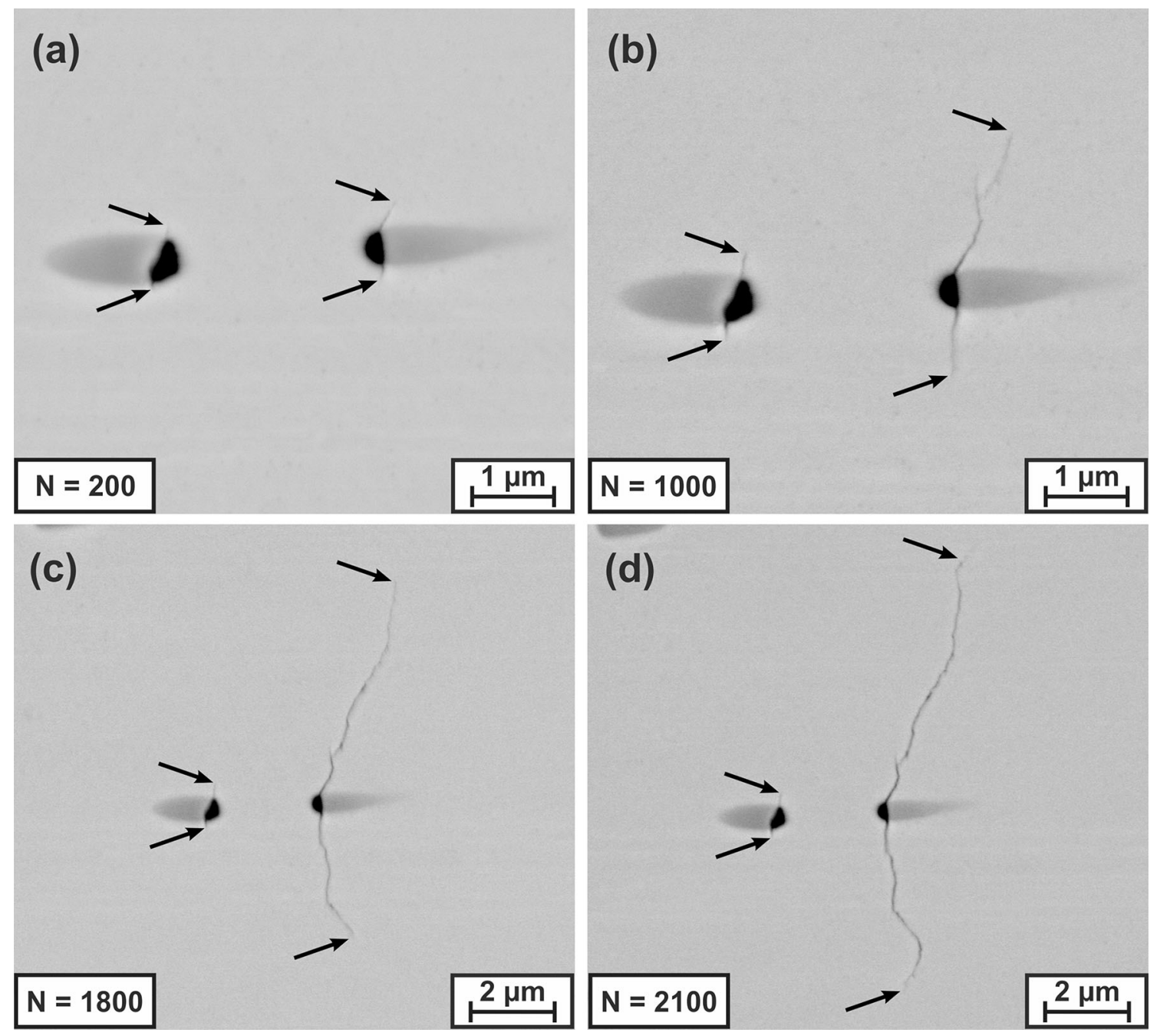

Fig. 3 Examples from short crack growth in pseudoelastic NiTi. Two cracks grow from particle void assemblies (PVAs). a 200 cycles. b 1000 cycles. c 1800 cycles. d 2100 cycles

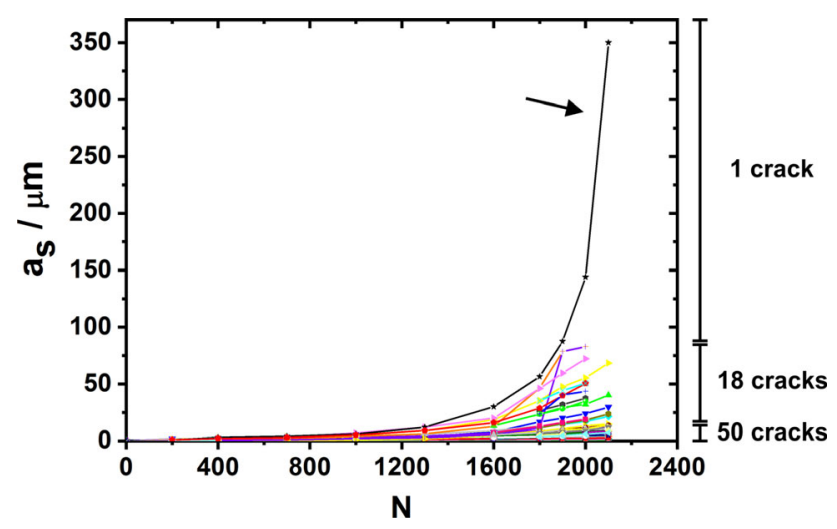

Fig. 4 Evolution of micro-crack lengths during structural fatigue testing of a pseudoelastic NiTi wire. For details see text

managed to grow by more than $100 \mu \mathrm{m}$ (Fig. 4). In fact, the long crack highlighted in Fig. 4 by an arrow finally caused the fatigue failure of the wire specimen. The behavior presented in Figs. 2, 3, and 4 merits further analysis. It is interesting to clarify which processes govern the growth of short cracks with sizes which match typical length scales involved in the formation of martensitic microstructures.

\section{Functional Fatigue}

In most SMAs, functional fatigue is directly caused by the accumulation of transformation-induced defects in the microstructure. Only a few exceptions exist, for example in $\beta$-Ti alloys, where $\omega$-phase and $\alpha$-Ti, which form during aging at elevated temperatures, affect martensitic transformations, e.g., [77-80]. In general, transformation-induced degradations can occur during (1) thermal cycling [81, 82], (2) thermal cycling under stresses [83-85], and (3) during mechanical (e.g., pull-pull) cycling of pseudoelastic 
SMAs [86, 87]. In the early 1970 s, Perkins [88] provided microstructural evidence for irreversible transformationrelated microstructural changes, which result in functional degeneration. Using transmission electron microscopy, it could be demonstrated that dislocations accumulate during thermal cycling in NiTi SMAs. It was suggested that these dislocations may provide back-stresses which support shape recovery processes. While this can be true for situations where a two-way effect is exploited after a thermomechanical training, a different view has been established today. In general, dislocations form during martensitic transformations to compensate for the crystallographic misfit between austenite and martensite [81, 82, 84, 85, 89]. Dislocations directly interact with austenite/martensite transformation fronts [90] and affect phase transformation behavior [81, 91, 92]. They even can stabilize martensite [93, 94]. Recently, a symmetry-dictated non-phase-transformation pathway during phase transformation cycling was proposed, which also could play a role as a potential mechanism leading to functional fatigue [30].
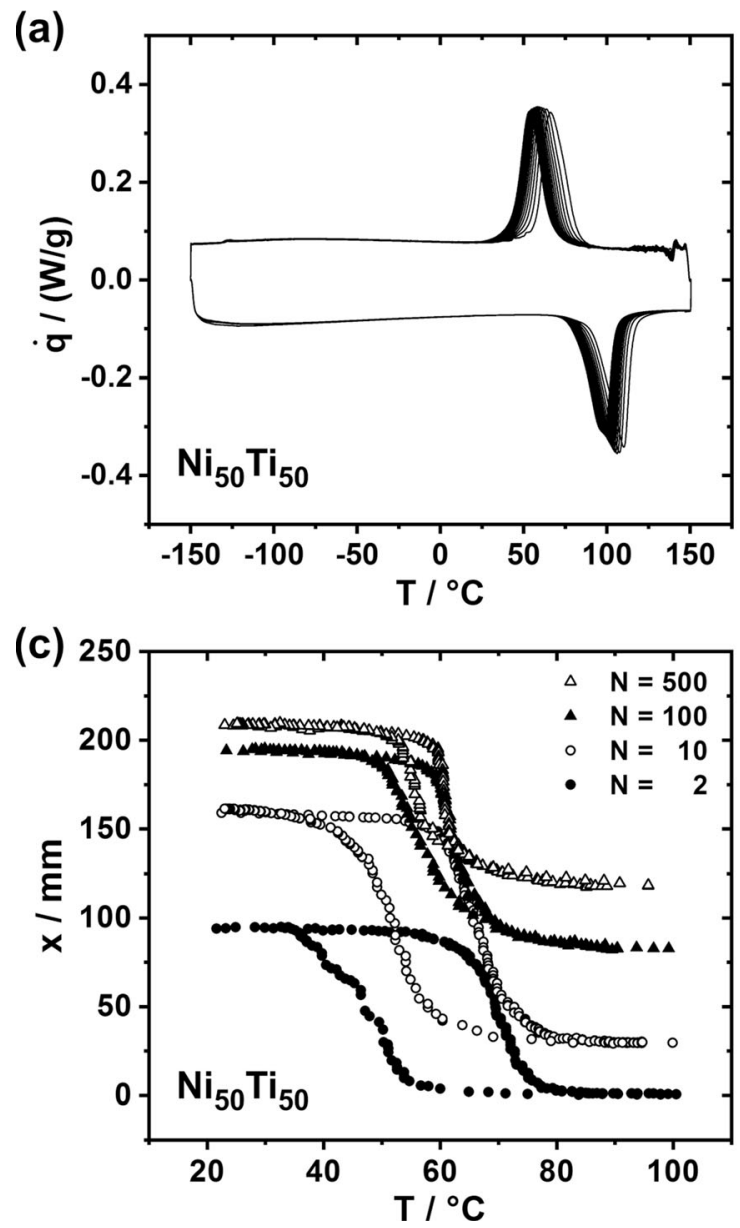

Figure 5 presents a few results on functional fatigue of binary $\mathrm{Ni}_{50} \mathrm{Ti}_{50}$ and ternary $\mathrm{Ni}_{40} \mathrm{Ti}_{50} \mathrm{Cu}_{10}$ SMAs. Two types of experiments were performed. First, both alloys were subjected to stress-free thermal cycling using differential scanning calorimetry (DSC). Second, spring actuators were prepared, and the functional performance of these springs was evaluated using a special test rig. Details on thermal cycling, alloy preparation/processing, and spring actuator fatigue testing are documented in the literature $[70,85,95,96]$. Figure $5 \mathrm{a}, \mathrm{b}$ present results from DSC experiments where 20 heating/cooling cycles were imposed. In the case of binary $\mathrm{NiTi}$, the peaks associated with the forward and reverse transformation shift towards lower temperatures during cycling (Fig. 5a). The NiTiCu SMA, Fig. 5b, shows two-step transformations, which are related to the formation of B19 and B19' martensites on cooling and to the reverse transformations on heating [97]. The data presented in Fig. 5a, b show that the NiTiCu SMA exhibits a significantly better functional stability as compared to binary NiTi, where transformation peaks shift to lower temperatures during cycling. Similar trends were
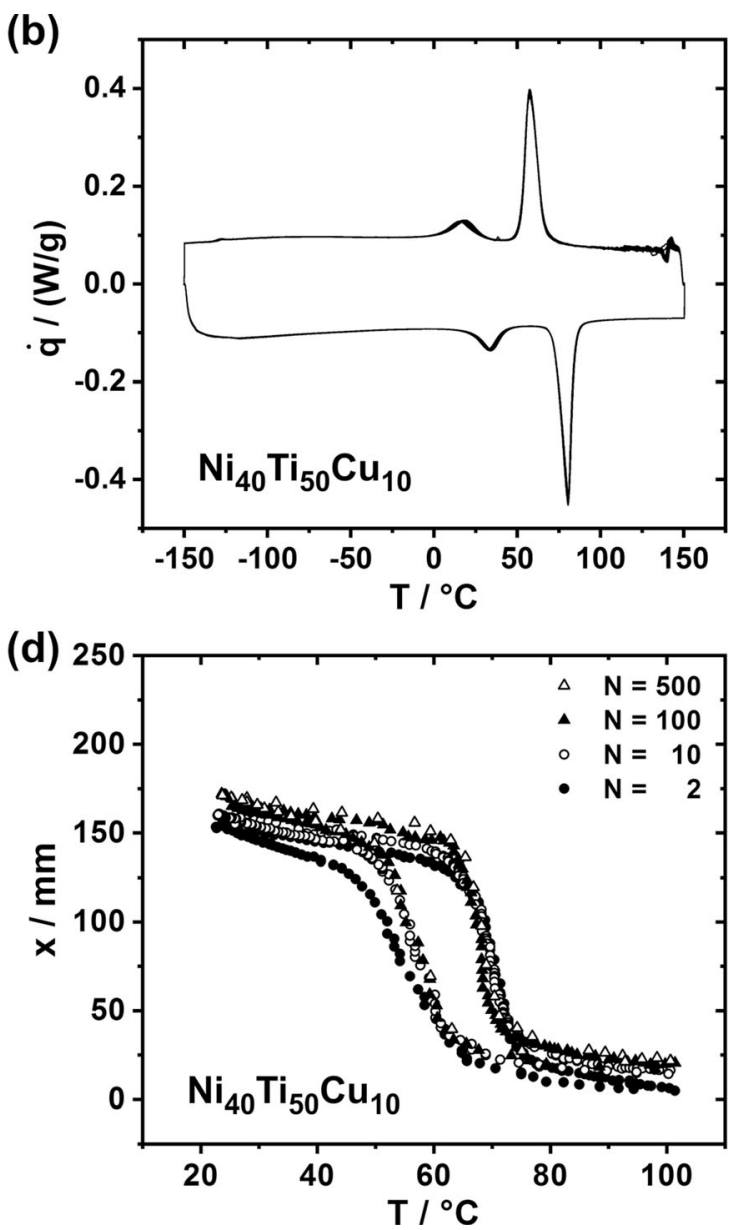

Fig. 5 Functional fatigue of NiTi and NiTiCu SMAs. a, b Stress-free thermal cycling. c, d Thermo-mechanical cycling of spring actuators (reprints from [85]) 
found for the performance of $\mathrm{NiTi}$ and $\mathrm{NiTiCu}$ spring actuators (Fig. 5c, d). Displacement/temperature hystereses of $\mathrm{NiTi}$ and $\mathrm{NiTiCu}$ spring actuators are presented in Fig. 5c, d [85], respectively. During heating, the actuators contract, which translates into a decrease of the displacement $(x)$. A total number of 500 thermo-mechanical actuation cycles $(N)$ was performed for both actuators. The data in Fig. $5 \mathrm{c}$, d show that functional fatigue during cycling results in a shift of the hysteresis curves to higher $x$ values. This means that the spring actuators permanently elongate through functional fatigue. Furthermore, a decrease of the hysteresis widths occurs during cycling. A detailed analysis of this behavior is presented in [85]. Most importantly, the functional stability of the NiTiCu actuator, Fig. 5 d, is significantly higher as that of binary NiTi (Fig. 5c). This is in line with what was previously observed for stress-free thermal cycling in the DSC (Fig. 5a, b).

The reason for the better functional stability of $\mathrm{NiTiCu}$ alloys is that these SMAs exhibit a better compatibility between the crystal lattices of austenite and martensite [98-100]. Therefore, fewer defects accumulate in the microstructure during phase transformation events. Grossmann et al. [85] were the first to document a direct evidence for the correlation between crystallographic compatibility and functional fatigue. This effect was later on confirmed in other studies, e.g., [84, 101-103]. One has to mention that crystallographic compatibility not only plays a role for thermal cycling with/without stresses (Fig. 5). Jaeger et al. [102] demonstrated that different degrees of crystallographic compatibility, which can be adjusted in binary NiTi by variations of the Ni concentration [14], lead to different mechanical stability during pseudoelastic cycling. Early studies on the relation between crystallographic compatibility and functional fatigue invoked the $\lambda_{2}$-misfit-parameter, which was introduced in [98, 99]. Since a few years, the effects of additional parameters, referred to as cofactor conditions, receive increasing scientific attention, e.g., [24, 104-110]. It has been discussed by Song et al. [104] that these cofactor conditions are highly relevant for functional fatigue. Shape memory materials have been identified which closely satisfy these supercompatibility conditions and which show a good functional stability, e.g., $\mathrm{Zn}_{45} \mathrm{Au}_{30} \mathrm{Cu}_{25}$ and $\left(\mathrm{Ti}_{54-}\right.$ $\left.\mathrm{Ni}_{34} \mathrm{Cu}_{12}\right)_{90} \mathrm{Nb}_{10} \quad[104,106-110]$. The compatibility between the lattices of austenite and martensite can be improved by compositional variations.

Tuning the crystallographic compatibility is not the only option available to reduce functional fatigue. The present state of knowledge shows that two different strategies can be applied: first, one can make phase transformation processes smoother to reduce irreversibility effects. Second, one can make the SMA stronger to increase fatigue resistance. The first strategy addresses crystallographic effects as has been discussed previously. The second strategy involves different measures which increase the resistance of the SMA with respect to plastic deformation. Grain size refinement has been shown to significantly reduce dislocation plasticity and thus to promote a stable functional performance, e.g., [95, 111, 112]. A second option is particle strengthening. It has been demonstrated for both binary and multi-component NiTi-based SMAs that precipitation hardening improves functional stability [103, 113-115]. A third option exists which may reduce functional fatigue: A few years ago, Firstov et al. $[116,117]$ introduced high-entropy SMAs. These materials receive increased scientific attention at present, e.g., [118-121]. Similar to conventional high-entropy alloys (HEAs), e.g., [122, 123], these materials are characterized by a large number of alloy components with equimolar compositions. The chemical nature of these SMAs may provide solid-solution-like strengthening effects. Further work is required to clarify how chemical complexity affects reversible and irreversible elemental processes of martensitic transformations.

\section{Coupling Between Structural and Functional Fatigue}

A strict differentiation between functional and structural fatigue is not always possible. Bigeon and Morin [124] studied the functional performance of $\mathrm{NiTiCu}$ and $\mathrm{CuZnAl}$ SMAs during thermal cycling under constant load. As a striking result, they observed that their samples broke after a certain number of cycles. The number of cycles to failure was depending on the loading stress, and increasing stress levels resulted in shorter fatigue lives. Bigeon and Morin [124] also showed that NiTiCu SMAs were less prone to this coupled functional/structural fatigue (CFSF) than CuZnAl alloys. Figure 6 presents SEM micrographs of $\mathrm{NiTi}$ wires after CFSF testing. The sample was loaded at a constant stress of $450 \mathrm{MPa}$ and subjected to heating/cooling cycles until fracture occurred after 10,328 cycles. Details on experiments are given elsewhere [125]. The fracture surface, Fig. 6a, shows that a large number of small cracks (highlighted by arrows) have formed in surface-near regions from where they grew inwards into the wire prior to rupture. Figure $6 \mathrm{~b}$ shows the skin surface of the wire. A high density of short cracks is visible, which grow perpendicular to the loading direction. The mechanism for the formation and growth of these cracks are not well understood at present. It has been suggested that cycling results in an increase of the surface roughness [126] which facilitates crack formation. Experimental studies are scarce at present, [115, 127-131]. Further work is required to analyze if and how incompatibilities between 

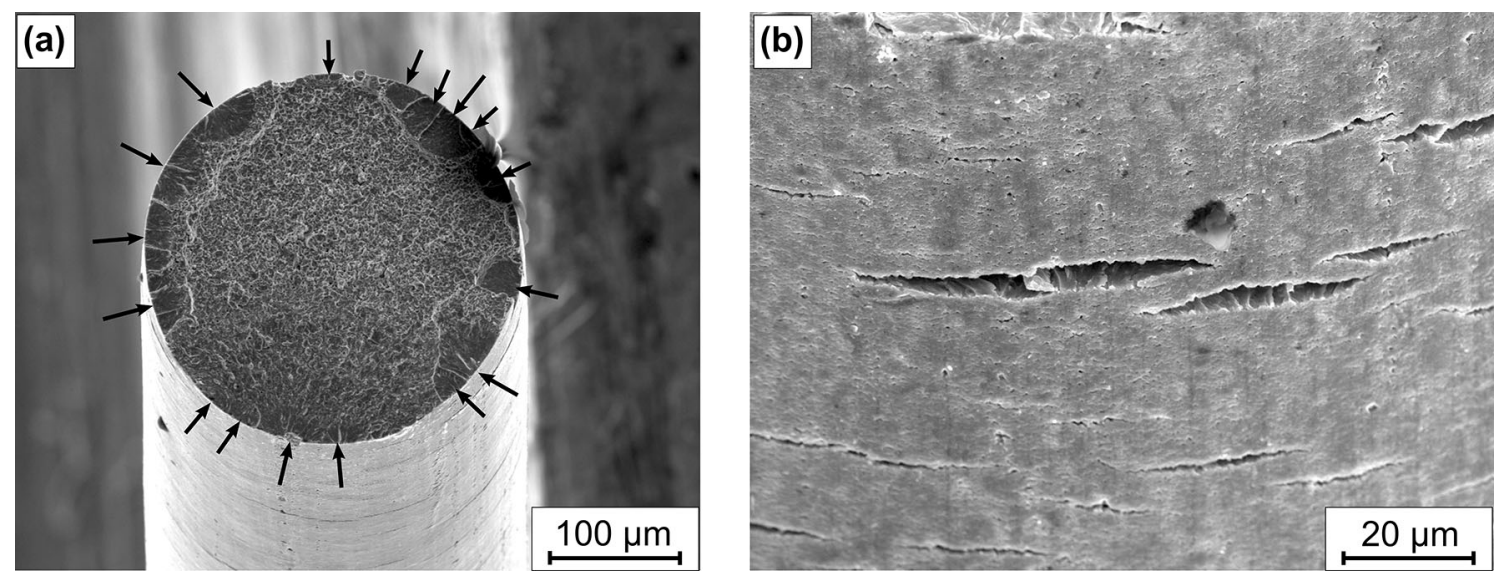

Fig. 6 Coupled functional and structural fatigue of NiTi SMA wires. a Fracture surface with crack initiation sites indicated by arrows. b Skin surface of the fractured wire showing high density of small micro-cracks

the lattices of martensite and austenite and related irreversible processes contribute to a coupling between functional and structural fatigue.

\section{Summary}

The present work stresses the importance of structural and functional fatigue in shape memory technology. Both limit the exploitable service lives of shape memory components. While a good state of knowledge has been established in both fields during the last decades, there are still aspects which require scientific attention. NiTi SMAs are prone to the formation of small cracks. There is a need for a better understanding of how micro-cracks can grow in a material which undergoes a stress-induced martensitic transformation, which redistributes stresses in the microstructure. The importance of functional fatigue has been highlighted. The functional stability of SMAs can be improved by (1) making phase transformations smoother and (2) by improving material strength to increase fatigue resistance. Further work is required to understand interactions between functional and structural fatigue and to clarify potential effects of solid-solution strengthening.

Acknowledgements Open Access funding provided by Projekt DEAL. The author acknowledges funding through the Collaborative Research Center SFB 459 (Shape Memory Technology) and through the Priority Program SPP 2006, "Legierungen mit komplexer Zusammensetzung - Hochentropielegierungen (CCA - HEA)", by the Deutsche Forschungsgemeinschaft (DFG). M. Rahim and A. Wieczorek are acknowledged for their support of the present study. B. Theren and B. Kuhlenkötter are acknowledged for providing the sample studied in Fig. 6.

Open Access This article is licensed under a Creative Commons Attribution 4.0 International License, which permits use, sharing, adaptation, distribution and reproduction in any medium or format, as long as you give appropriate credit to the original author(s) and the source, provide a link to the Creative Commons licence, and indicate if changes were made. The images or other third party material in this article are included in the article's Creative Commons licence, unless indicated otherwise in a credit line to the material. If material is not included in the article's Creative Commons licence and your intended use is not permitted by statutory regulation or exceeds the permitted use, you will need to obtain permission directly from the copyright holder. To view a copy of this licence, visit http://creativecommons. org/licenses/by/4.0/.

\section{References}

1. Mohd Jani J, Leary M, Subic A, Gibson MA (2014) A review of shape memory alloy research, applications and opportunities. Mater Des 56:1078-1113

2. Duerig T, Pelton A, Stöckel D (1999) An overview of Nitinol medical applications. Mater Sci Eng A 273-275:149-160

3. Van Humbeeck J (1999) Non-medical applications of shape memory alloys. Mater Sci Eng A 273-275:134-148

4. Duerig TW (2002) The use of superelasticity in modern medicine. MRS Bull 27(2):101-104

5. Song G, Ma N, Li HN (2006) Applications of shape memory alloys in civil structures. Eng Struct 28(9):1266-1274

6. Miyazaki S, Otsuka K (1989) Development of shape memory alloys. ISIJ Int 29(5):353-377

7. Bhattacharya K (2004) Microstructure of martensite: why it forms and how it gives rise to the shape-memory effect. Oxford University Press, Oxford

8. Otsuka K, Ren X (2005) Physical metallurgy of Ti-Ni-based shape memory alloys. Prog Mater Sci 50(5):511-678

9. Wechsler MS, Lieberman DS, Read TA (1953) On the theory of the formation of martensite. Trans Am Inst Min Metall Eng 197(11):1503-1515

10. Nishida M, Nishiura T, Kawano H, Inamura T (2012) Self-accommodation of $\mathrm{B} 19^{\prime}$ martensite in $\mathrm{Ti}-\mathrm{Ni}$ shape memory alloys-Part I. Morphological and crystallographic studies of the variant selection rule. Philos Mag 92(17):2215-2233

11. Ball JM, James RD (1987) Fine phase mixtures as minimizers of energy. Arch Ration Mech Anal 100(1):13-52

12. Salzbrenner RJ, Cohen M (1979) On the thermodynamics of thermoelastic martensitic transformations. Acta Metall Mater 27(5):739-748 
13. Khalil-Allafi J, Dlouhy A, Eggeler G (2002) $\mathrm{Ni}_{4} \mathrm{Ti}_{3}$-precipitation during aging of NiTi shape memory alloys and its influence on martensitic phase transformations. Acta Mater 50(17):4255-4274

14. Frenzel J, George EP, Dlouhy A, Somsen C, Wagner MFX, Eggeler G (2010) Influence of $\mathrm{Ni}$ on martensitic phase transformations in $\mathrm{NiTi}$ shape memory alloys. Acta Mater 58(9):3444-3458

15. Frenzel J, Wieczorek A, Opahle I, Maaß B, Drautz R, Eggeler G (2015) On the effect of alloy composition on martensite start temperatures and latent heats in Ni-Ti-based shape memory alloys. Acta Mater 90:213-231

16. Waitz T, Kazykhanov V, Karnthaler HP (2004) Martensitic phase transformations in nanocrystalline NiTi studied by TEM. Acta Mater 52(1):137-147

17. Waitz $\mathrm{T}$ (2005) The self-accommodated morphology of martensite in nanocrystalline NiTi shape memory alloys. Acta Mater 53(8):2273-2283

18. Chen YC, Molnarova O, Tyc O, Kaderavek L, Heller L, Sittner $P$ (2019) Recoverability of large strains and deformation twinning in martensite during tensile deformation of NiTi shape memory alloy polycrystals. Acta Mater 180:243-259

19. Funakubo H (1987) Shape memory alloys. Gordon and Breach, New York

20. Lagoudas DC (2008) Shape memory alloys: modeling and engineering applications. Springer, New York

21. Tugrul HO, Saygili HH, Velipasaoglu MS, Kockar B (2019) Comparison of the transformation behavior of cold rolling with aging and hot extrusion with aging processed $\mathrm{Ni}_{50.3} \mathrm{Ti}_{29.7} \mathrm{Hf}_{20}$ high temperature shape memory alloy. Smart Mater Struct 28(10): 10

22. Ronald N, Tiffany B, Santo P (2006) NiTi-based high-temperature shape-memory alloys. In: Soboyejo WO, Srivatsan TS (eds) Advanced structural materials. CRC Press, Boca Raton

23. Ma J, Karaman I, Noebe RD (2010) High temperature shape memory alloys. Int Mater Rev 55(5):257-315

24. Bucsek AN, Hudish GA, Bigelow GS, Noebe RD, Stebner AP (2016) Composition, compatibility, and the functional performances of ternary NiTiX high-temperature shape memory alloys. Shape Mem Superelast 2(1):62-79

25. Rahim M, Frenzel J, Frotscher M et al (2013) Impurity levels and fatigue lives of pseudoelastic NiTi shape memory alloys. Acta Mater 61(10):3667-3686

26. Robertson SW, Pelton AR, Ritchie RO (2012) Mechanical fatigue and fracture of Nitinol. Int Mater Rev 57(1):1-36

27. Pelton AR (2011) Nitinol fatigue: a review of microstructures and mechanisms. J Mater Eng Perform 20(4-5):613-617

28. Wu Y, Yaacoub J, Brenne F, Abuzaid W, Canadinc D, Sehitoglu H (2019) Deshielding effects on fatigue crack growth in shape memory alloys-a study on $\mathrm{CuZnAl}$ single-crystalline materials. Acta Mater 176:155-166

29. Baxevanis T, Lagoudas DC (2015) Fracture mechanics of shape memory alloys: review and perspectives. Int $\mathrm{J}$ Fract 191(1-2):191-213

30. Gao Y, Casalena L, Bowers ML, Noebe RD, Mills MJ, Wang Y (2017) An origin of functional fatigue of shape memory alloys. Acta Mater 126(Supplement C):389-400

31. Wang J, Sehitoglu H (2014) Martensite modulus dilemma in monoclinic NiTi-theory and experiments. Int J Plast 61:17-31

32. Stebner AP, Vogel SC, Noebe RD et al (2013) Micromechanical quantification of elastic, twinning, and slip strain partitioning exhibited by polycrystalline, monoclinic nickel-titanium during large uniaxial deformations measured via in-situ neutron diffraction. J Mech Phys Solids 61(11):2302-2330
33. Stebner AP, Bigelow GS, Yang J et al (2014) Transformation strains and temperatures of a nickel-titanium-hafnium high temperature shape memory alloy. Acta Mater 76:40-53

34. Birk T, Biswas S, Frenzel J, Eggeler G (2016) Twinning-induced elasticity in NiTi shape memory alloys. Shape Mem Superelast 2(2):145-159

35. Laplanche G, Birk T, Schneider S, Frenzel J, Eggeler G (2017) Effect of temperature and texture on the reorientation of martensite variants in NiTi shape memory alloys. Acta Mater 127:143-152

36. Prokoshkin SD, Korotitskiy AV, Brailovski V, Turenne S, Khmelevskaya IY, Trubitsyna IB (2004) On the lattice parameters of phases in binary $\mathrm{Ti}-\mathrm{Ni}$ shape memory alloys. Acta Mater 52(15):4479-4492

37. Haberland C, Elahinia M, Walker JM, Meier H, Frenzel J (2014) On the development of high quality NiTi shape memory and pseudoelastic parts by additive manufacturing. Smart Mater Struct 23(10): 104002

38. Meier H, Haberland C, Frenzel J (2012) Structural and functional properties of NiTi shape memory alloys produced by selective laser melting. CRC Press-Taylor and Francis Group, Boca Raton

39. Chen XZ, Liu K, Guo W, Gangil N, Siddiquee AN, Konovalov S (2019) The fabrication of NiTi shape memory alloy by selective laser melting: a review. Rapid Prototyp J 25(8):1421-1432

40. Wang XB, Kustov S, Van Humbeeck J (2018) A short review on the microstructure, transformation behavior and functional properties of NiTi shape memory alloys fabricated by selective laser melting. Materials 11(9): 14

41. Undisz A, Schrempel F, Wesch W, Rettenmayr M (2012) Mechanism of oxide layer growth during annealing of NiTi. J Biomed Mater Res A 100A(7):1743-1750

42. Habijan T, Glogowski T, Kühn S et al (2011) Can human mesenchymal stem cells survive on a NiTi implant material subjected to cyclic loading? Acta Biomater 7(6):2733-2739

43. Es-Souni M, Es-Souni M, Fischer-Brandies H (2005) Assessing the biocompatibility of NiTi shape memory alloys used for medical applications. Anal Bioanal Chem 381(3):557-567

44. Qian S, Geng Y, Wang Y et al (2016) A review of elastocaloric cooling: materials, cycles and system integrations. Int J Refrig 64:1-19

45. Fähler S, Rößler UK, Kastner O et al (2012) Caloric effects in ferroic materials: new concepts for cooling. Adv Eng Mater 14(1-2):10-19

46. Frenzel J, Eggeler G, Quandt E, Seelecke S, Kohl M (2018) High-performance elastocaloric materials for the engineering of bulk- and micro-cooling devices. MRS Bull 43(4):280-284

47. Sehitoglu H, Wu Y, Ertekin E (2018) Elastocaloric effects in the extreme. Scr Mater 148:122-126

48. Wu Y, Ertekin E, Sehitoglu H (2017) Elastocaloric cooling capacity of shape memory alloys-role of deformation temperatures, mechanical cycling, stress hysteresis and inhomogeneity of transformation. Acta Mater 135:158-176

49. Eggeler G, Hornbogen E, Yawny A, Heckmann A, Wagner M (2004) Structural and functional fatigue of NiTi shape memory alloys. Mater Sci Eng A 378(1-2):24-33

50. Chemisky Y, Hartl DJ, Meraghni F (2018) Three-dimensional constitutive model for structural and functional fatigue of shape memory alloy actuators. Int J Fatigue 112:263-278

51. Niendorf T, Krooss P, Batyrsina E et al (2015) Functional and structural fatigue of titanium tantalum high temperature shape memory alloys (HT SMAs). Mater Sci Eng A 620:359-366

52. König D, Zarnetta R, Sayan A, Brunken H, Ludwig A (2011) Phase transformation, structural and functional fatigue 
properties of Ti-Ni-Hf shape memory thin films. Acta Mater 59(8):3267-3275

53. Dimakos K, Mariotto A, Giacosa F (2016) Optimization of the fatigue resistance of Nitinol stents through shot peening. Procedia Struct Integr 2:1522-1529

54. Pelton AR, Schroeder V, Mitchell MR, Gong XY, Barney M, Robertson SW (2008) Fatigue and durability of Nitinol stents. J Mech Behav Biomed 1(2):153-164

55. Robertson SW, Launey M, Shelley O et al (2015) A statistical approach to understand the role of inclusions on the fatigue resistance of superelastic Nitinol wire and tubing. J Mech Behav Biomed 51:119-131

56. McKelvey AL, Ritchie RO (2001) Fatigue-crack growth behavior in the superelastic and shape-memory alloy Nitinol. Metall Mater Trans A 32(3A):731-743

57. Rahim M, Frenzel J, Frotscher M, Heuwer B, Hiebeler J, Eggeler G (2013) Bending rotation HCF testing of pseudoelastic $\mathrm{Ni}-\mathrm{Ti}$ shape memory alloys. Materialwiss Werkst Techn 44(7):633-640

58. Wagner M, Sawaguchi TS, Kaustrater G, Höffken D, Eggeler G (2004) Structural fatigue of pseudoelastic NiTi shape memory wires. Mater Sci Eng A 378(1-2):105-109

59. Takeda K, Matsui R, Tobushi H, Homma S, Hattori K (2015) Enhancement of fatigue life in TiNi shape memory alloy by ultrasonic shot peening. Mater Trans 56(4):513-518

60. Zhang Z, Frenzel J, Somsen C, Pesicka J, Eggeler J (2005) On the formation of $\mathrm{TiC}$ crystals during processing of NiTi shape memory alloys. In: Karas V (ed) Trends in crystal growth research. Nova Science Publishers, New York

61. Frenzel J, Zhang Z, Somsen C, Neuking K, Eggeler G (2007) Influence of carbon on martensitic phase transformations in $\mathrm{NiTi}$ shape memory alloys. Acta Mater 55(4):1331-1341

62. Zhang ZH, Frenzel J, Neuking K, Eggeler G (2005) On the reaction between NiTi melts and crucible graphite during vacuum induction melting of NiTi shape memory alloys. Acta Mater 53(14):3971-3985

63. Gollerthan S, Young ML, Baruj A, Frenzel J, Schmahl WW, Eggeler G (2009) Fracture mechanics and microstructure in NiTi shape memory alloys. Acta Mater 57(4):1015-1025

64. Ungár T, Frenzel J, Gollerthan S, Ribárik G, Balogh L, Eggeler $\mathrm{G}$ (2017) On the competition between the stress-induced formation of martensite and dislocation plasticity during crack propagation in pseudoelastic NiTi shape memory alloys. J Mater Res 23:1-10

65. Mughrabi H (2010) Fatigue, an everlasting materials problemstill en vogue. Procedia Eng 2(1):3-26

66. Christ H-J (2009) Ermüdungsverhalten metallischer Werkstoffe. Wiley-VCH, Weinheim

67. Frotscher M, Nörtershäuser P, Somsen C, Neuking K, Böckmann R, Eggeler G (2009) Microstructure and structural fatigue of ultra-fine grained NiTi-stents. Mater Sci Eng A 503(1-2):96-98

68. Paris PC, Gomez MP, Anderson WE (1961) A rational analytic theory of fatigue. Trends Eng 13:9-14

69. Rahim M (2013) Untersuchungen zum Einfluss von Kohlen- und Sauerstoff-Verunreinigungen auf das Ermüdungsverhalten von pseudoelastischen NiTi-Formgedächtnislegierungen. Dr.-Ing. Thesis, Universitätsverlag, Bochum

70. Grossmann C, Frenzel J, Sampath V et al (2008) Processing and property assessment of NiTi and NiTiCu shape memory actuator springs. Materialwiss Werkst Techn 39(8):499-510

71. Wagner MFX (2006) New aspects of bending rotation fatigue in ultra-fine-grained pseudo-elastic NiTi wires. Int $\mathrm{J}$ Mater Res 97(12):1687-1696
72. Wagner MFX, Eggeler G (2006) Stress and strain states in a pseudoelastic wire subjected to bending rotation. Mech Mater 38(11):1012-1025

73. Frenzel J, Neuking K, Haberland C, Eggeler G (2007) In: Miyazaki S (ed) SMST 2007: proceedings of the international conference on shape memory and superelastic technologies. ASM International

74. Suresh S (1983) Crack deflection-implications for the growth of long and short fatigue cracks. Metall Trans A 14(11):2375-2385

75. McEvily AJ, Eifler D, Macherauch E (1991) An analysis of the growth of short fatigue cracks. Eng Fract Mech 40(3):571-584

76. King A, Ludwig W, Herbig M et al (2011) Three-dimensional in situ observations of short fatigue crack growth in magnesium. Acta Mater 59(17):6761-6771

77. Kim HY, Miyazaki S (2018) Ni-free Ti-based shape memory alloys. Butterworth-Heinemann, Oxford

78. Buenconsejo PJS, Kim HY, Miyazaki S (2009) Effect of ternary alloying elements on the shape memory behavior of Ti-Ta alloys. Acta Mater 57(8):2509-2515

79. Paulsen A, Frenzel J, Langenkämper D et al (2019) A kinetic study on the evolution of martensitic transformation behavior and microstructures in $\mathrm{Ti}-\mathrm{Ta}$ high-temperature shape-memory alloys during aging. Shape Mem Superelast 5:16-31

80. Ferrari A, Paulsen A, Langenkämper D et al (2019) Discovery of omega-free high-temperature Ti-Ta shape memory alloys from first-principles calculations. Phys Rev Mater 3(10):103605

81. Miyazaki S, Igo Y, Otsuka K (1986) Effect of thermal cycling on the transformation temperatures of Ti-Ni alloys. Acta Metall Mater 34(10):2045-2051

82. Zhang J, Somsen C, Simon T et al (2012) Leaf-like dislocation substructures and the decrease of martensitic start temperatures: a new explanation for functional fatigue during thermally induced martensitic transformations in coarse-grained Ni-rich Ti-Ni shape memory alloys. Acta Mater 60(5):1999-2006

83. Canadinc D, Trehern W, Ozcan H et al (2017) On the deformation response and cyclic stability of $\mathrm{Ni}_{50} \mathrm{Ti}_{35} \mathrm{Hf}_{15}$ high temperature shape memory alloy wires. Scr Mater 135:92-96

84. Atli KC, Franco BE, Karaman I, Gaydosh D, Noebe RD (2013) Influence of crystallographic compatibility on residual strain of TiNi based shape memory alloys during thermo-mechanical cycling. Mater Sci Eng A 574:9-16

85. Grossmann C, Frenzel J, Sampath V, Depka T, Eggeler G (2009) Elementary transformation and deformation processes and the cyclic stability of $\mathrm{NiTi}$ and $\mathrm{NiTiCu}$ shape memory spring actuators. Metall Mater Trans A 40(11):2530-2544

86. Olbricht J, Yawny A, Condo AM, Lovey FC, Eggeler G (2008) The influence of temperature on the evolution of functional properties during pseudoelastic cycling of ultra fine grained NiTi. Mater Sci Eng A 481:142-145

87. Sedmák P, Šittner P, Pilch J, Curfs C (2015) Instability of cyclic superelastic deformation of NiTi investigated by synchrotron X-ray diffraction. Acta Mater 94:257-270

88. Perkins J (1973) Lattice transformations related to unique mechanical effects. Metall Trans 4(12):2709-2721

89. Norfleet DM, Sarosi PM, Manchiraju S et al (2009) Transformation-induced plasticity during pseudoelastic deformation in Ni-Ti microcrystals. Acta Mater 12:3549-3561

90. Simon T, Kroger A, Somsen C, Dlouhy A, Eggeler G (2010) On the multiplication of dislocations during martensitic transformations in NiTi shape memory alloys. Acta Mater 58(5):1850-1860

91. Airoldi G, Rivolta B (1988) Thermal cycling and intermediate R-phase in NiTi system. Phys Scr 37(6):891-893

92. Liu Y, Laeng J, Chin TV, Nam TH (2008) Partial thermal cycling of NiTi. J Alloy Compd 449(1-2):144-147 
93. Liu YN, Tan G, Miyazaki S (2006) Deformation-induced martensite stabilisation in [100] single-crystalline Ni-Ti. Mater Sci Eng A 438:612-616

94. Wagner MFX, Nayan N, Ramamurty U (2008) Healing of fatigue damage in NiTi shape memory alloys. J Phys D 41(18):4

95. Maass B, Burow J, Frenzel J, Eggeler G (2009) On the influence of crystal defects on the functional stability of NiTi based shape memory alloys. In: ESOMAT 2009-8th European symposium on martensitic transformations, $\mathrm{p} 954$

96. Frenzel J, Neuking K, Eggeler G (2004) Induction melting of NiTi shape memory alloys the influence of the commercial crucible graphite on alloy quality. Materialwiss Werkst Techn 35(5):352-358

97. Nam TH, Saburi T, Shimizu K (1990) Cu-content dependence of shape memory characteristics in $\mathrm{Ti}-\mathrm{Ni}-\mathrm{Cu}$ alloys. Mater Trans JIM 31(11):959-967

98. Ball JM, James RD (1992) Proposed experimental tests of a theory of fine microstructure and the 2-well problem. Philos Trans R Soc A 338(1650):389-450

99. James RD, Zhang Z (2005) In: Manosa L, Planes A, Saxena A (eds) Magnetism and structure in functional materials. Springer, New York

100. Cui J, Chu YS, Famodu OO et al (2006) Combinatorial search of thermoelastic shape-memory alloys with extremely small hysteresis width. Nat Mater 5(4):286-290

101. Zarnetta R, Takahashi R, Young ML et al (2010) Identification of quaternary shape memory alloys with near-zero thermal hysteresis and unprecedented functional stability. Adv Funct Mater 20(12):1917-1923

102. Jaeger S, Maaß B, Frenzel J et al (2015) On the widths of the hysteresis of mechanically and thermally induced martensitic transformations in $\mathrm{Ni}-\mathrm{Ti}$ based shape memory alloys. Int $\mathrm{J}$ Mater Res 106(10):1029-1039

103. Chluba C, Ge WW, de Miranda RL et al (2015) Ultralow-fatigue shape memory alloy films. Science 348(6238):1004-1007

104. Song YT, Chen X, Dabade V, Shield TW, James RD (2013) Enhanced reversibility and unusual microstructure of a phasetransforming material. Nature 502(7469):85-88

105. Chen X, Srivastava V, Dabade V, James RD (2013) Study of the cofactor conditions: conditions of supercompatibility between phases. J Mech Phys Solids 61(12):2566-2587

106. Ni XY, Greer JR, Bhattacharya K, James RD, Chen X (2016) Exceptional resilience of small-scale $\mathrm{Au}_{30} \mathrm{Cu}_{25} \mathrm{Zn}_{45}$ under cyclic stress-induced phase transformation. Nano Lett 16(12):7621-7625

107. Gu H, Bumke L, Chluba C, Quandt E, James RD (2018) Phase engineering and supercompatibility of shape memory alloys. Mater Today 21(3):265-277

108. Pang EL, McCandler CA, Schuh CA (2019) Reduced cracking in polycrystalline $\mathrm{ZrO}_{2}-\mathrm{CeO}_{2}$ shape-memory ceramics by meeting the cofactor conditions. Acta Mater 177:230-239

109. Jetter J, Gu HL, Zhang HL et al (2019) Tuning crystallographic compatibility to enhance shape memory in ceramics. Phys Rev Mater 3(9):7

110. Tong YX, Gu HL, James RD, Qi WY, Shuitcev AV, Li L (2019) Novel $\mathrm{TiNiCuNb}$ shape memory alloys with excellent thermal cycling stability. J Alloy Compd 782:343-347

111. Delville R, Malard B, Pilch J, Sittner P, Schryvers D (2011) Transmission electron microscopy investigation of dislocation slip during superelastic cycling of $\mathrm{Ni}-\mathrm{Ti}$ wires. Int $\mathrm{J}$ Plast 27(2):282-297

112. Chluba C, Ge W, Dankwort T et al (2016) Effect of crystallographic compatibility and grain size on the functional fatigue of sputtered TiNiCuCo thin films. Philos Trans R Soc A 374(2074):20150311
113. Gall K, Maier H (2002) Cyclic deformation mechanisms in precipitated NiTi shape memory alloys. Acta Mater 50(18):4643-4657

114. Ortega AM, Tyber J, Frick CP, Gall K, Maier HJ (2005) Cast NiTi shape-memory alloys. Adv Eng Mater 7(6):492-507

115. Karakoc O, Hayrettin C, Evirgen A et al (2019) Role of microstructure on the actuation fatigue performance of Ni-rich NiTiHf high temperature shape memory alloys. Acta Mater 175:107-120

116. Firstov GS, Kosorukova TA, Koval YN, Verhovlyuk PA (2015) Directions for high-temperature shape memory alloys' improvement: straight way to high-entropy materials? Shape Mem Superelast 1(4):400-407

117. Firstov GS, Kosorukova TA, Koval YN, Odnosum VV (2015) High entropy shape memory alloys. Mater Today Proc 2:499-503

118. Piorunek D, Frenzel J, Somsen K, Jöns N, Eggeler G (2020) Chemical complexity, microstructure and martensitic transformation in high entropy shape memory alloys. Intermetallics 122:106792

119. Chang SH, Lin PT, Tsai CW (2019) High-temperature martensitic transformation of CuNiHfTiZr high- entropy alloys. Sci Rep 9:7

120. Glowka K, Zubko M, Swiec P, Prusik K, Dercz G, Stroz D (2019) Microstructure analysis of equiatomic multi-component $\mathrm{Ni}_{20} \mathrm{Ti}_{20} \mathrm{Ta}_{20} \mathrm{Co}_{20} \mathrm{Cu}_{20}$ alloy. Arch Metall Mater 64(2):785-789

121. Kosorukova TA, Gerstein G, Odnosum VV, Koval YN, Maier HJ, Firstov GS (2019) Microstructure formation in cast TiZrHfCoNiCu and CoNiCuAlGaIn high entropy shape memory alloys: a comparison. Materials 12(24):4227

122. George EP, Raabe D, Ritchie RO (2019) High-entropy alloys. Nat Rev Mater 4(8):515-534

123. Cantor B, Chang ITH, Knight P, Vincent AJB (2004) Microstructural development in equiatomic multicomponent alloys. Mater Sci Eng A 375:213-218

124. Bigeon MJ, Morin M (1996) Thermomechanical study of the stress assisted two way memory effect fatigue in TiNi and CuZnAl wires. Scr Mater 35(12):1373-1378

125. Fleczok B, Rathmann C, Otibar D, Weirich A, Kuhlenkötter B (2017) Impact of different electrical time-based activations on NiTi shape memory alloys. IOP Conf Ser Mater Sci Eng 216(1):012008

126. Treadway J, Abolmaali A, Lu F, Aswath P (2015) Tensile and fatigue behavior of superelastic shape memory rods. Mater Des 86:105-113

127. Calhoun C, Wheeler R, Baxevanis T, Lagoudas DC (2015) Actuation fatigue life prediction of shape memory alloys under the constant-stress loading condition. Scr Mater 95:58-61

128. Lagoudas DC, Miller DA, Rong L, Kumar PK (2009) Thermomechanical fatigue of shape memory alloys. Smart Mater Struct 18(8):12

129. Phillips FR, Wheeler RW, Geltmacher AB, Lagoudas DC (2019) Evolution of internal damage during actuation fatigue in shape memory alloys. Int J Fatigue 124:315-327

130. Jape S, Baxevanis T, Lagoudas DC (2018) On the fracture toughness and stable crack growth in shape memory alloy actuators in the presence of transformation-induced plasticity. Int J Fract 209(1-2):117-130

131. Baxevanis T, Parrinello AF, Lagoudas DC (2016) On the driving force for crack growth during thermal actuation of shape memory alloys. J Mech Phys Solids 89:255-271

Publisher's Note Springer Nature remains neutral with regard to jurisdictional claims in published maps and institutional affiliations. 